\title{
Thoughts on Principal's Teaching Leadership and Its Cultivation
}

\author{
Yang Lingling ${ }^{1 *}$, Li Jiang ${ }^{2}$ \\ ${ }^{1}$ Bansomdejchaopraya Rajabhat University, Bangkok, Thailand. \\ ${ }^{2}$ Army Logistics Academy. Chongqing, China. \\ * Yang Lingling. Email: 289446857@qq.com.
}

\begin{abstract}
The principal's teaching leadership is one of the principal's core leadership abilities, which is of great significance to improve the school's teaching efficiency and promote the overall development of students. This article starts with the analysis of the connotation and influencing factors of the principal's teaching leadership, and analyzes the current situation of the principal's teaching leadership. At present, the principal's teaching leadership has problems in teaching leadership concepts, professional knowledge, teaching practice, and evaluation systems. In response to these problems, it is proposed to strengthen training and learning, update the teaching leadership concept; improve professional quality, implement teaching practice; update the teaching evaluation system, etc., in order to provide suggestions for improving the teaching leadership of principals.
\end{abstract}

Keywords: Principal's teaching leadership, Connotation, Influencing factors, Cultivation

\section{INTRODUCTION}

With the continuous deepening of education reform, improving school teaching efficiency and promoting the overall development of students have become the top priority of the principal's work. As one of the principal's core leadership abilities, principal's teaching leadership is of great significance to improve the school's teaching effectiveness.

The "Standards for the Professionalization of Principals of Compulsory Education Schools" issued by the Ministry of Education clearly requires principals to adhere to the principle of "ethics first, educationoriented, leading development, ability-oriented, and lifelong learning" to enhance the personal abilities of principals in many ways.

Among them, the three principles of educationoriented, ability-oriented, and lifelong learning are directly related to the teaching leadership of the principal. The requirements of the school education in the new era for the teaching leadership of the principal are constantly increasing; the teaching leadership of the principal has also become a key research area of the Ministry of Education.

This paper starts with the basic connotation and influencing factors of the principal's teaching leadership, looks for the problems of the principal's teaching leadership, and then proposes ways to cultivate the principal's teaching leadership.

\section{THE CONNOTATION OF THE PRINCIPAL'S TEACHING LEADERSHIP}

Teaching is the core and most important work of the school, the principal's teaching leadership is also the principal's most important ability. This article summarizes its connotation by consulting the research conclusions of domestic and foreign scholars.

The concept of teaching leadership originated in the "Effective Schools" movement in the United States [1], and subsequent scholars continued to conduct in-depth research on it. Early foreign scholars defined the principal's teaching leadership mainly on the "teaching" of teachers and the "learning" of students. De Bevoise [2] proposed that teaching leadership means that in order to improve the teaching quality of teachers and students' academic performance, the principals or other relevant personnel implement developmental school goals, provide teaching and learning resources, and formulate reasonable teacher training plans, guidance and evaluation of teachers' teaching improvement measures, etc.. Hallinger [3] constructed a "threedimensional, ten-function" teaching leadership model, 
proposed the principal to lead the management of teaching work, and promote the "teaching" of teachers and the "learning" of students. Heck et al. [4] believed that teaching leadership is a collection of various strategies and work taken by the principal to improve the teaching level. Subsequently, scholars incorporated the professional development of teachers into the connotation of the principal's teaching leadership. King[5] proposed that teaching leaders should also consider teacher professional development and the construction of a professional learning community while paying attention to teacher teaching and student learning. Goddard[6] believed that the principal's teaching leadership is the principal's ability to support and promote the cooperative development of teachers, improve teachers' collective effectiveness, and promote student learning ability and school effectiveness.

On the basis of western research, Chinese scholars have carried out relevant research in combination with the country's national conditions. The definition of principals' teaching leadership can be roughly classified into three types: ability theory, influence theory and joint force theory.

The principal's teaching leadership is ability. Zhao De cheng[7-8] put forward a localized teaching leadership model from multiple perspectives such as the upper concept of teaching leadership, design-related situational factors, and the ultimate goal, and summarized it as: the leader influences teachers, students and other interests, in order to achieve the mission and vision of the school, etc., and promote students' learning and development abilities. Dai Ruihua[9] proposed that the teaching leadership of the principal is to promote the school reform and improve the ability of teachers' teaching and students' learning level by constructing the relationship of mutual influence.

The principal's teaching leadership is an influence. Zheng Jinzhou [10] believes that the principal's teaching leadership is mainly used in teaching values, teaching goals, core teaching issues, teaching organization, teaching conditions, and teaching quality. It is the principal's influence in leading teaching changes, leading teaching reforms, and promoting the development of teachers and students.

The principal's teaching leadership is a comprehensive ability. Long Yong [11] summarized the research on the teaching leadership of principals and defined its connotation from three aspects of behavior process, ability and function. He believed that principals exert influence at the level of behavior process and achieve educational goals; they exert decision-making power at the level of ability, promote the development of teachers and students, and exert leadership at the functional level to achieve teaching effectiveness.
From the perspectives of domestic and foreign scholars, it can be seen that the principal's teaching leadership is both ability, influence and comprehensive ability. The teaching leadership of principals should focus on leading teachers' teaching and students' learning, mobilizing teachers to form a cooperative community, creating a common vision for student learning and teacher development, optimizing curriculum settings, creating a harmonious campus culture, and improving teaching effectiveness.

\section{INFLUENCING FACTORS OF THE PRINCIPAL'S TEACHING LEADERSHIP}

As the global education reform continues to deepen, the environment faced by education managers is becoming more and more complex and changeable. The analysis of the leadership process needs to be conducted not only from the perspective of the interaction between leadership behavior and the situation, but also from the perspective of the leader's personal characteristics. Domestic and foreign scholars' research on the influencing factors of principals' teaching leadership is mostly interpreted from two perspectives: the interaction between leadership behavior and context and the personal characteristics of leaders.

Foreign research divides the influence factors of principals' teaching leadership into internal factors and external factors. Internal factors mainly refer to personal background and external factors mainly refer to relevant situational factors inside and outside the school. Bossert [12] pointed out that the principal's teaching management behavior will be affected by personal characteristics, regional characteristics and external characteristics. On this basis, Murphy [13] further unified the regional characteristics and external characteristics into the school context, and divided them into the school internal context and the school external context, and subdivided the principal's personal characteristics into six categories: experience, knowledge, individual characteristics, beliefs and values. Gurr [14] believes that the influence of the situation, the principal's values, school vision, school ability, personal support and investment, teaching and learning are the six major factors that affect the effectiveness of the principal's teaching leadership. Hallinger[15] summarized the influencing factors of the principal's teaching leadership into nine aspects: the principal's personal values and beliefs, the principal's personal knowledge, social culture, organizational system, community characteristics, school culture, school cultural atmosphere, academic structure and process and faculty and staff, this research is a summary of predecessors' influence on the principal's teaching leadership. The principal's personal values, beliefs and personal knowledge belong to the principal's personal background factors, and the school's culture, 
organizational system, faculty, etc. belong to both the inside and outside school relevant situational factors.

According to the research results of domestic scholars, the factors affecting the teaching leadership of the principal are roughly divided into school organizational factors and principal personal factors. School organizational factors mainly include school level, school location, and school period. Personal factors mainly include the principal's gender, educational background, professional title, teaching age, and personal power. Zhao Qian [16] constructed a regression model and found out that school level, location, and funding are the basic environmental factors that affect the principal's teaching leadership. The lower the school grade is, the better the local economic condition is, the more the funding is, the more the principal pays attention to teaching leadership. Management maturity, management style and personal power have a significant impact on the principal's teaching leadership. Principals with more mature management are able to devote more energy to teaching leadership, principals with mixed management of authority and democracy; principals with both macro management and micromanagement have more frequent teaching leadership behaviors. Ma Jing [17] believes that teaching age, professional title and educational background have a significant impact on the teaching leadership of principals. Principals with 7-25 years of teaching experience have the highest teaching leadership level. Principals with higher professional titles and academic qualifications have stronger teaching leadership.

\section{PROBLEMS OF THE PRINCIPAL'S TEACHING LEADERSHIP}

\subsection{The teaching leadership concept needs to be updated and strengthened}

As the leader of teaching implementation and reform, principals need to possess advanced teaching leadership concepts and transform them into practical actions. Some principals only regard themselves as teaching administrators and believe that teaching is the responsibility of teachers. They only need to deploy personnel to ensure the smooth progress of teaching activities, and weaken or even abandon the responsibility of the principals to lead the teaching work.

In addition, some principals have misunderstandings about the connotation of teaching leadership, who believes that teaching leadership is merely a task of teaching management, as long as they do well in teaching management affairs such as class attendance, class assessment, classroom inspections, etc., while ignoring the connotation that the principal's teaching leadership needs to give play to the "comprehensive power" of the school, teachers and students.

\subsection{Incomplete professional knowledge, divorced from teaching practice}

In order for principals to exert their teaching leadership, they need to have a comprehensive understanding of professional knowledge and practice. Some principals are limited by their own disciplines, and do not have a deep understanding of the subject knowledge of "different subjects", the problem of strong teaching leadership in "same subject" and weak teaching leadership in "different subjects" arises.

At the same time, the principal shoulders the important task of seeking the development of the school. $\mathrm{He}$ needs to be responsible for school administrative work, participating in various conferences, administrative duties, and affairs review, etc., which occupies lots of time and energy. Some principals no longer engaged in curriculum teaching and other work, divorced from teaching practice, unable to fully grasp the first-hand teaching situation, which hindering the improvement of the principal's teaching leadership.

\subsection{The teaching leadership evaluation system is not scientific}

An effective evaluation system is an important guarantee for the generation of teaching leadership. At present, many schools still use summative test scores as the only method of teaching evaluation, and do not scientifically use process and summative diversified methods for evaluation; blindly emphasize the supremacy of scores, and regard students' test scores as the only criterion for evaluating teachers' teaching quality and principals' teaching leadership. The teaching evaluation system lacks integrity and scientificity.

The unscientific evaluation system makes it easy for principals and teachers to focus only on student test scores and neglect the cultivation and improvement of overall quality. Students cannot develop in an all-round way, let alone cultivate interest in multiple fields. A series of chain reactions caused by the unscientific evaluation system affect the improvement of principals' teaching leadership.

\section{CULTIVATION OF THE PRINCIPAL'S TEACHING LEADERSHIP}

\subsection{Strengthen training and learning, update teaching leadership concepts}

Carry out targeted training and learning for principals' teaching leadership. Focusing on the principal's professional quality requirements in building a culture of educating people, teaching leadership 
courses, leading teachers to grow, and optimizing internal management, conduct concentrated and intensified training, and continuously strengthen the concept of teaching leadership. Targeted strengthen personal learning, expand horizons, update teaching leadership concepts from time to time, give full play to the role of teaching leadership, and mobilize schools, teachers and students to exert their educational efforts.

\subsection{Improve professional quality and implement teaching practice}

Actively learn relevant subject professional knowledge, break through subject professional barriers, and make up for missing items and shortcomings. Strengthen the learning of basic theories and practical experience of curriculum teaching, and become experts in teaching. Continuously deepen the teaching reform, systematically and systematically build in terms of teaching philosophy, teaching content, student training goals, curriculum structure, curriculum standards, and curriculum evaluation system to meet the needs of individualized and differentiated learning of students.

\subsection{Update and improve the teaching evaluation system}

Actively improve and perfect the teaching evaluation system, and formulate a scientific and reasonable teaching evaluation system. Adhere to the method of combining formative and summative evaluation, pay attention to the comprehensive development of students and the cultivation of comprehensive abilities, pay attention to achievements while taking into account their innovative performance.

Adjusting the external environment so that teachers are responsible for teaching work, while paying attention to the development of teachers in a scientific and reasonable manner, cultivating their teaching leadership, meeting their development needs, fully mobilizing their enthusiasm, and improving the quality and effectiveness of school teaching is an important way to enhance the leadership of the principal.

\section{CONCLUSION}

This article starts with the research status of the basic connotation and influencing factors of principals' teaching leadership, and deeply analyzes and finds out the problems existing in principals' teaching leadership such as the teaching leadership concept needs to be updated and strengthened, professional knowledge is not comprehensive and divorced from teaching practice, teaching leadership evaluation system is unscientific. The way such as strengthening training and learning, updating teaching leadership concepts, improving professional quality, implementing teaching practice, updating the teaching evaluation system were proposed to improve the teaching leadership of principals.

\section{REFERENCES}

[1] Lv Zhenyun. Research on the Teaching Leadership of Primary and Secondary School Principals and the Improvement Strategy [J]. Modern Communication, 2020, 11:141-142.

[2] De Bevoise, W. Synthesis of research on the principal as instructional leader[J]. Educational Leadership,1984,41(5):14-20.

[3] Hallinger P,Murphy J. Assessing the Instructional Management Behavior of Principals[J].Elementary School Journal, 1985,86 (2) :217-247.

[4] Heck, R. H., Larsen, T. J., \& Marcoulides, G. A. Instructional leadership and school achievement:Validation of a causal model[J].Educational Administration Quarterly, 1990,26(2):94-125.

[5] King, D. The changing shape of leadership[J]. Educational Leadership, 2002,59(8), 61-63.

[6] Goddard, R., Goddard, Y., Kim, E. S., \& Miller, R.A theoretical and empirical analysis of the roles of instructional leadership, teacher collaboration, and collective efficacy beliefs in support of student learning $[\mathrm{J}]$. American Journal of Education, 2015,121(4), 501-530.

[7] Zhao Decheng, Ma Xiaorong. Problems and prospects in the research of teaching leadership [J]. Foreign Educational Research, 2016, 43(9): 60-70.

[8] Zhao Decheng. Teaching leadership: connotation, evaluation and future research directions [J]. Foreign Educational Research, 2013, 40 (4): 96103.

[9] Dai Ruihua, Wan Heng. Research on Principal's teaching leadership in Constructing Learning Community $[\mathrm{J}]$. Teacher Education Research,2016(2): 59-63.

[10] Zheng Jinzhou. A Preliminary Study of Principal's teaching leadership $[\mathrm{J}]$. Journal of Hebei Normal University (Educational Science Edition), 2012(11): 42-45.

[11] Long Yong, Sun Jinming. A Review of the Research on the Teaching Leadership of Primary and Secondary School Principals in the Past Ten Years $[\mathrm{J}]$. Primary and Secondary School Management, 2012(11): 29-33.

[12] Bossert, S. T., Dwyer, D. C., Rowan, B., \& Lee, G. $\mathrm{V}$. The instructional management role of the 
principal[J]. Educational Administration Quarterly, 1982,18(3), 34-64.

[13] Murphy, J., Elliott, S. N., Goldring, E., \& Porter, A. C. Leadership for learning: A research-based model and taxonomy of behaviors[J]. School Leadership and Management, 2007,27(2), 179-201.

[14] Gurr, D., Drysdale, L., \& Mulford, B. Models of successful principal leadership[J]. School leadership and management, 2006,26(4), 371-395.

[15] Hallinger, P., \& Hosseingholizadeh, R. (2019). Exploring instructional leadership in Iran: A mixed methods study of high-and low-performing principals. Educational Management Administration \& Leadership, 1-22. doi:10.1177/1741143219836684.

[16] Zhao Qian. Research on the Teaching Leadership of Principals $[\mathrm{M}]$. Beijing: Beijing Normal University Press, 2018: 99.

[17] Ma Jing. Research on the Teaching Leadership of Rural Primary and Secondary School Principals[J]. Primary and Secondary School Principals, 2019(9): 11-16. 